\title{
Business Ethics of Government Employees and Future Lawyers in Thailand: A Study of Age, Gender, Management Experience, and Education
}

\author{
Bahaudin G. Mujtaba \\ Nova Southeastern University \\ 3301 College Avenue, Fort Lauderdale, FL. 33314-7796 USA \\ Tel: (954)-262-5045Ｅ-mail: mujtaba@nova.edu \\ Dr. Frank J. Cavico \\ Nova Southeastern University \\ 3301 College Avenue, Fort Lauderdale, FL. 33314-7796 USA \\ Tel: (954)-262-5000Ｅ-mail: cavico@nova.edu \\ Dr. Jatuporn Sungkhawan \\ Southeast Bangkok College \\ 290 Sunpawut Road; Bangna, Bangkok, Thailand 10260 \\ Tel: (662)-7447356 E-mail: dr_jatuporn@yahoo.com
}

\begin{abstract}
Ethical maturity and moral behavior are of concern to all managers and government officials, and even more so in Asian economy where some aspects of the economy seem to "go underground" without any taxation or proper credit to the owners or copyright holders. This research surveyed managers and employees in the Thai public work environment to measure their Personal Business Ethics Scores (PBES) to see if age, education, working in government, management experience, or gender makes a difference in making more ethical decisions. The responses of 304 government employees are compared to the PBES means of 216 law students to measure individual commitment to integrity, honesty, and observance of the laws regulating current business activities.

The results of this research suggest that gender and work experience in the public sector are significant factors in the moral development of the respondents. This study contributes to the theory of moral development and the body of knowledge regarding the relationship of certain key variables to moral cognizance and ethical behavior, particularly regarding managers, government employees, and their gender.
\end{abstract}

Keywords: Maturity, Moral development, Management, ethics, Public sector experience, Education

\section{Introduction}

A review of a national or international newspaper, skimming through articles, listening to the radio or watching television, and talking to people in the community, will demonstrate that people are concerned about the illegal and unethical decisions of workers and managers (Mujtaba, Pattaratalwanich and Chawavisit, 2009; Cavico and Mujtaba, 2009). Regardless of the culture or country, perhaps there are some common temptations that drive people toward unethical actions. One of these behavior "drivers" might be greed, which is influencing people to behave unethically; or perhaps it could be a person's gender, level of education, age, or seniority that leads one to make ethical lapses in judgment. A key research question, therefore, would be to see if work experience, age, education, and gender make a difference in the ethical decision-making of managers. Consequently, this research is designed to compare the Personal Business Ethics Scores (PBES) of managers and associates in Thailand. Building on the theory of cognitive moral development, the purpose of this study is to determine whether government work experience, education, age, and gender are related to ethical decision-making.

\section{Ethics, Values, and Moral Development}

Moral development is the development of a person's ability to distinguish right from wrong, to develop a system of ethical values, and to learn to act morally (Mujtaba and Cavico, 2009). Moral development refers to progressive and continuous changes from the beginning of life until the end. Moral development occurs through the process of socialization, education, aging, and experience (Kohlberg, 1969, 1984). Each individual has the ability to think about his or her own thought process, which is known as "self-awareness." It is the "self-awareness" ability which enables people to make significant advances from generation to generation. Moral behavior is a function of one's 
past experience with similar situations where a person has learned to behave in a morally acceptable manner (Danon-Leva, 2006). Society influences behavior through formal and informal education as well as experience, since people grow older each day. It is believed that science, religion, culture, standards of good and bad, and other forms of behavior in society, are passed on by nurture (that is, they are learned) and not by nature. The authors believe that each individual has the ability to think about his or her own thought process. Moral character is an aspect of personality, which can structure a person's moral, ethical, and personal beliefs and values. In general, a person may be deemed moral when he or she behaves ethically. Moral behavior appears to be a function of one's past experience with similar situations in which a person has learned to behave morally. Social and moral potentialities may be nourished best through brain development between birth and maturity, supplemented by the process of education (Mujtaba, 2010). Moral learning, accordingly, is not much different from any other form of learning. Society, regardless of whether one is living in the Eastern or Western culture, influences the behavior of its members through education and experience as people grow older.

Values are rankings or priorities that a person establishes for one's norms and beliefs; they are ordered by relative importance. Values often are controversial because the norms and beliefs that one person holds in high esteem may conflict with different norms and beliefs that another person holds in equally high esteem (Mujtaba, Chawavisit and Pattaratalwanich, 2010). Values are acquired through childhood experiences, education, and learning from one's ancestors; and this social learning supplies one's norms and values, which are an important part of one's culture and the customs of that culture (Huang, 2006). Moral values are the rankings or priorities that a person establishes for one's moral norms and moral beliefs. Huang states that "the value system has a strong effect on what is perceived as right or wrong" (2006, p. 16). Making moral rules and moral judgments based on ethical reasoning from ethical principles and ranking values accordingly are highly intellectual exercises, and indicate that a person has a high degree of moral development and maturity.

The preceding discussion was premised principally on Western philosophy and ethics. Yet is it incumbent on the U.S. academic, researcher, and business person studying or doing business overseas to be cognizant of other philosophical and ethical approaches. The Chinese during the Sixth century B.C. developed two different philosophical schools - Taoism and Confucianism. Huang (2006) points out that "these two philosophical thinking have had profound, immense influences on the Chinese culture, and to a broader extent, the East. They still dominate central ideologies of some Asian countries such as China, Taiwan, Japan, and Singapore" (p. 32). Venezia (2004) explains the major tenets of these philosophies: "Taoism was concerned with observing nature and the discovery of its way, referred to as Tao. Confucianism was the philosophy of social organization, of common sense, and practical knowledge. One of Confucianism's main purposes was to form an ethical basis for the traditional Chinese family system" (p. 26). Venezia further explains: "Taoism emphasized seeking nature and quietism, rather than forcing to get what you want. It focused on teaching the proper way to live in accordance with nature and the importance of inner peace and being true to one's nature" (2004, p. 27). Taoism underscored selflessness as an essential quality of life; altruistic ideals are thus an integral part of the teachings of Taoism (Huang, 2006). The goal is to perfect oneself by the self-cultivation of virtue and also to benefit others in a selfless manner (Huang, 2006). Confucianism's "main concern was to cultivate the living humanity of the individual and society in harmony, according to the Way of the ideal course of moral conduct" (Venezia, 2004, p. 27). Harmony and balance are exemplified by the superseding forces of Ying and Yang, which govern and hold together every aspect of life, including business, particularly negotiations, where the Ying-Yang principle is viewed as a fundamental principle (Danon-Leva, 2006). A central tenet of Confucianism is the belief that "man" is essentially good (Venezia, 2004). A person, therefore, should learn, reflect on, and attain moral ideals (Huang, 2006). Another important Confucian principle is proper role relationships, for example, between father and son and husband and wife; and if everyone plays his or her role properly, for example, the father is kind to the son, and the son is dutiful to the father, then the entire society will remain in a harmonious state (Huang, 2006). Huang explained that "Confucius' main concern was to cultivate the living humanity of the individual and society in harmony, according (to) the way or the ideal course of moral conduct" (2006, p. 35). Virtuous behavior will bring about individual success and social harmony. Education, therefore, should inculcate moral learning and moral self-cultivation (Huang, 2006). Both the Confucian and Taoist philosophies have strongly influenced Eastern life, thought, and morals. In contrast to Western philosophy, Confucianism is little concerned with metaphysical issues or religious or spiritual attainments; rather, it emphasizes moral behavior and the "right" relationships for a person; cultivation of virtue is also a key principle of Confucianism. The emphasis is on inculcating lessons in practical ethics without any religious foundation or content. Central elements of Confucian teaching, according to Venezia (2004), are: 1) social hierarchy and social stability; 2) natural love and obligations between family members, which form the basis of the general morality, and which extend to society as a whole as an extended family; and 3) benevolence, which includes being kind, trustworthy, and forthright, as well as clever and wise. Venezia (2004) relates that Confucianism has influenced people in East Asia 
for more than 2000 years. Venezia (2004) also points out that Taiwan ranks very high in "Confucian Work Dynamism," which is the "...search for virtues such as persistence, ordering relationships by status and observing this order, thrift, and having a sense of shame" (p. 30). Ames (2009) maintains that the Confucianism perspective has two dimensions which have ramifications for global business people and managers: 1) the homogenization of knowledge, processes, and skills that enable people to accomplish things and enhance the quality of their life; and 2) mutual accommodation of different cultures (Ames, 2009). Confucianism, therefore, with its emphasis on harmony and the mutual accommodation of different cultures and peoples, has benefitted most Asian cultures in today's diverse, international marketplace and workplace.

\subsection{The Thai Culture}

Thailand is naturally part of the Eastern cultural tradition, and thus has certain Asian cultural components that socialize and influence people behaviors (Mujtaba, Chawavisit and Pattaratalwanich, 2010; Mujtaba, 2008). Thailand is considerably different from Western societies in terms of fundamental values as well as work-related values (Mujtaba, Pattaratalwanich and Chawavisit, 2009). According to Kini, et al (2004), "Thais' dominant values are caring for others and the quality of life, while Americans' dominant values are success, money, and material things" (p. 96). In particular, the Thai people are more collectivist and more accepting of power than people in the United States. Thailand also has a more "feminine" culture in that Thai people tend to prefer more nurturing behavior over assertive conduct, and they thus make more of an effort to avoid situations of uncertainly. Singhapakdi, et al (2000) agree: "Thailand is fundamentally different from the U.S. and most Western countries....Thailand is a more collectivist and a less masculine society than the U.S. and many other Western countries" (p. 273). Kini, et al (2004) further state: "The social structure in Thailand and the U.S. are quite different. In Thailand, the society respects its elders, superiors, and patrons more so than in the U.S. The social status, seniority, and personal connections govern the relationships in Thailand, creating moderately high gap between people with power and people without power...” (pp. 94-95). There are more community influences in Thailand; and core values are considered to be collectivistic, fatalistic, and externally power controlled (Kini, et al, 2004). Accordingly, "because of these traits, for a collectivist Thai, approval and compliance of his/her behavior with others is more important than his/her own attitude toward certain behavior" (Kini, et al, 2004, p. 96). However, people in the U.S. are "...individualistic and with strong internal locus of control, believe they have the dominion over nature, and feel their own attitude toward the behavior is more important than others" (Kini, et al, p. 96). Moreover, people in the U.S. "typically...are self-assertive and strive for personal achievement. They are materialistic, and material rewards such as salary, promotion, and rewards enhance their motivation. Thais, on the other hand, give priority to maintaining good relationships since loyalty and trust to seniors are important to them, rather than task achievement and material rewards" (Kini, et al, 2004, p. 96).

Suwannachin (2003) points out that on Hofstede's "culture map" Thai people score high in Power Distance, Collectivism, Uncertainty Avoidance, and Feminity (p. 36). The high Power Distance ranking influences the behavior of Thai people, including administrators, teachers, students, and parents, in that they always must show respect toward those people in "senior status in all social relationships" (Suwannachin, p. 37). This showing of respect "...results in a pervasive, socially-legitimated, expectation that decisions should be made by those in positions of authority" (Suwannachin, p. 37). However, there are reciprocal obligations in Thai culture, that is, "the relationship between superiors and subordinates means that there are obligations on both sides, and the Thai subordinates expect to be treated with respect" (Suwannachin, p. 38). Generally speaking, superiors tend to be older. The Cognitive Moral Development theory posits that as a person increases in age, his or her capability and level of moral reasoning should concomitantly and progressively increase too. Furthermore, as a person increases in age, so does the complexity of the moral questions that a person will confront; and accordingly moral reasoning should increase with age (Mujtaba et al., 2009). Yet perhaps age in combination with education would demonstrate a stronger link to moral maturity than between "mere" age and moral maturity (Mobley, 2002, p. 74; Mujtaba, 1997, p. 24). Heron (2006) pointed to a study which reported that $38 \%$ of the variance in the Defining Issues Test (moral cognizance) scores can be explained by the variables of age and education (p. 87). Therefore, the study for this article focused on the following hypothesis:

Hypothesis 1 - Individuals who are 25 years of age or younger will have Personal Business Ethics Scores (PBES) that are equivalent to or greater than those individuals who are 26 years of age or older.

The high Collectivism characteristic of Thai culture "...shapes the context for change by locating it more in the group than in individuals. This tend(s) to exhibit a strong 'we' as opposed to 'I' mentality" (Suwannachin, 2003, p. 37). High Uncertainty Avoidance "...means that Thais are strongly socialized to conform to group norms, traditions, and rules and regulations. They evince a stronger tendency to seek stability than to be creative, and they find change disruptive and more disturbing than people in lower uncertainty avoidance cultures" (Suwannachin, p. 37). Finally, 
"the feminine aspects of the culture lead Thais to place an extremely high value on social relationships, harmony, (and) conflict avoidance. Thais also place a great deal of emphasis on living and working in a pleasurable atmosphere, and on fostering a strong spirit of community through pleasant and congenial social relations" (Suwannachin, pp. 37-38).

Resanond (2002) agrees that "Thailand is an 'authority ranking culture' in which vertical collectivism is emphasized"; but he also notes that in Thailand, "...probably because it is at the crossroads of many competing cultures, the Thais follow fewer rules than do most authority ranking cultures" (p. 16). The hallmark of an "authority ranking culture" is the existence of "dynamic and two-way relationship between a superior and others" (Resanond, p. 17). The authority aspect of Thai culture is reflected in its education system, which "stresses memorization and the taking of copious notes in lectures. Discussion is not emphasized" (Resanond, p. 17). Another key concept in Thailand is taking another person's feelings into account. Even in the superior-subordinate relationship, “...there are obligations on both sides, and Thai subordinates expect to be treated with respect" (Resanond, 2002, p. 18).

Khruasuwan (2000) emphasizes the "clientship" nature of Thai society. Clientship, Khruasuwan defines "...as a relationship between two persons who are not kin but stand in a position of superiority-inferiority to one another....The best description of clientship may be a lop-sided friendship when friendship means instrumental friendship, a personal relationship in which striving for access to resources (natural or social) as a vital part" (2000, p. 82). Clientship can also be deemed to be a "Patron-Client" relationship, which, Khruasuwan notes "...affects relationships in modern organizations in Thailand" (p. 83). A very important norm is that the inferior must respect the superior. Khruasuwan explains that "respect, in Thai society, implies obedience and following rules of etiquette such as not arguing with the superior, not giving unasked-for advice, not addressing him by his name and many other norms" (p. 85). Another expression of this relationship is gift-giving and gift-receiving, which in Thai society are very important acts. When one gives a gift, or does something to benefit another, the recipient of this gift or favor, is obligated to do something of benefit in return (Khruasuwan, 2000).

Khruasuwan (2000) relates some significant differences between Thai and U.S. culture regarding work motivation: "In the US, a highly individualistic culture, employees tend to work for self-advancement, material rewards, increased status and self-actualization...; however, in the collectivist culture of Thailand, it is the duty of everyone (employees, for example) to accumulate the BUN (merit) in order to belong to the merit group; in return, the superior should recognize the good effort and work from the subordinates" (pp. 101-02). Furthermore, "in the individualistic US environment, work must satisfy the workers, and it is important to satisfy individual needs...But for the Thai, in a collectivist environment, it is important to satisfy the group, to give more rather than less; working with the BUN (do good things) means you will receive good in return, and that is how the team works with enthusiasm" (Khruasuwan, p. 102). Khruasuwan also compares the power-distance between U.S. and Thai work relationships: The U.S. has a low power-distance relationship. There thus is cooperation and teamwork; but one major goal of such cooperation is to promote self-advancement and self-fulfillment. However, in Thailand, which is a high power-distance culture, the emphasis is on the Patron-Client, superior-subordinate relationship, which entails a traditional, formal, hierarchical structure. Khruasuwan (2000), moreover, compares decision-making styles: "In the US, a more masculine culture than Thai culture, tough values like assertiveness, performance, success and competition, are valued. The Thai culture can be considered more feminine (than US culture), with greater value placed on maintaining warm personal relationships with a Patron-client situation (follow the leader); the relationships in this society require obedience along with other rules of etiquette, such as respect for one's superior, not giving unasked-for advice, and not arguing with the superior" (pp. 102-03). Since the Thai government encourages, socializes, and expects managers and workers to follow the strict norms of their culture, it is assumed that they will be the best examples of the culture in Thailand. Therefore, the study for this article focused on the following hypothesis:

Hypothesis 2 - Government employees will have Personal Business Ethics Scores that are similar to the PBES means of law students.

Thai people have been strongly influenced by Asian philosophies, which are often integrated in their formal and informal education (Mujtaba, Chawavisit and Pattaratalwanich, 2010; Mujtaba, Pattaratalwanich and Chawavisit, 2009). Since education makes people more knowledgeable, then more formal schooling should lead to better decisions. Accordingly, people with higher levels of formal education and more experience should be more morally aware, one would assume. One principal purpose of this work, therefore, is to discern if education and ethics training relate to morality and ethical behavior. That is, does the education level of a person, including particularly ethics education and ethics training, relate to that person's moral maturity and business ethics? 
Is there a relationship between ethics and morality? That is, is there a relationship between education and moral maturity and business ethics? Furthermore, is there a relationship between specifically ethics education and/or ethics training and the aforementioned variables? Most professional, business, and public administration schools today have mandatory courses on ethics or business ethics on the undergraduate as well as graduate level. Moreover, corporations and government organizations have such courses too as well as ethics training and also diversity and sensitivity training. Furthermore, most companies and government entities today have codes of ethics or codes of conduct as well as concomitant ethics code communication, education, and training. Do all or any of these extensive education efforts affect the moral maturity, moral cognizance, and moral behavior of people? If there is not a significant demonstrable relationship, then perhaps the schools' and the organizations' resources could be spent more profitably elsewhere, perhaps in inculcating students, employees, and business people on the criminal law, particularly the now very draconian penalties for certain types of "white-collar" crime, such as bribery.

\subsection{Education and Ethics}

Some researchers claim that such factors as gender, age, and education make a difference in the ethical maturity of individuals in Thailand as well as people in other countries. Perhaps there is a direct relationship between the human development index and a country's corruption index. The literacy rates for Thailand in 2002 was $95.5 \%$ (UNESCO, 2002). UNESCO's data estimates that about 2.1 million people in Thailand are illiterate. Of course, the government's ideal goal has been to have one-hundred percent literacy rate in the country for the year 2010 and beyond. Regardless of whether this ideal goal is achieved, research supports that education of a country's citizens is an important variable for the development of a country. Furthermore, educated people are in a better position to make ethical choices. Therefore, the study for this article focused on the following hypothesis:

Hypothesis 3 -Individuals who have five or more years of formal college education (masters degree and above) will have Personal Business Ethics Scores that are equivalent to the PBES means of individuals who have four years of college education or less (bachelors degree or less).

\subsection{Gender and Ethics}

Some of the past researchers report that gender does not affect the moral reasoning of individuals. However, others conclude that males and females pass through different stages of moral development at different age categories (Gilligan, 1982, 1977; Mujtaba, 1997). Gilligan (1982) claims that while males are learning rules as part of their moral development, females are learning about intimacy, caring, helping, and relationships.

Respect for leaders, Rassameesukhanon (2008) emphasized, is another fundamental component of Thai society and culture, especially since "Thailand is a highly centralized society with clear delineations of status and authority" (p. 85). Rassameesukhanon (2008) conducted a study of leaders and employees of different age groups working in different industries in Bangkok, Thailand. Rassameesukhanon (2008) sampled 250 leaders and 250 employees using an instrument designed specifically for the study which sought responses from the leaders and employees on their perceptions of ideal and actual leaders. Rassameesukhanon found that males and females had a different notion of "ideal" and actual leaders. The statistical result indicated a significant difference between how male and female leaders perceived ideal leadership. Rassameesukhanon (2008) stated that the female leaders perceived ideal leadership in a more "idealistic" way, which Rassameesukhanon described as respect for people and their "human aspirations" that connects leaders to employees (p. 85). So, gender emerged as a significant variable, at least in this Thailand leadership study. Marta and Singhapakdi (2005) underscore the "greater acceptance of power differentials in Thai culture" (p. 572). They also state that this acceptance could explain why Thai business people "...would tend not to perceive themselves as moral actors in a particular situation, which would, in turn, explain their lower perception of moral intensity" (Marta and Singhapakdi, 2005, p. 572).

Overall though, many researchers conclude that males and females can and do think of moral problems from different points of view, depending on the situation and context being considered (Mujtaba, 2010). Managers tend to respond to ethical dilemmas situationally, regardless of gender, it is argued. Therefore, the study for this article focused on the following hypothesis:

Hypothesis 4 - Males will have Personal Business Ethics Scores that are equivalent to the PBES means of females.

\subsection{Management and Ethics Education}

Managers often receive special training about management, leadership, and effective decision-making as they move up through the ranks. Consequently, they often make better ethical decisions than their employees, perhaps due to the fact that they think differently about the impact of each decision. Similarly, women often appear to be more ethically mature than their male counterparts, perhaps due to their ability to think more about the impact of their decisions on others. As such, some studies tend to link the ethical maturity levels of women with executives. A 
study (Mujtaba, 2010) compared Fortune 1000 executives with MBA students and found that female MBA students' ethical judgments were much closer to executives' than male MBAs' judgments. The study also found that female MBA students possessed significantly different and less tolerant ethical values than male MBA students possessed. Mujtaba (2010) studied managers and employees in the retail environment and reported that managers did have higher scores on ethical maturity. In the younger sector of the sample, female respondents had a higher level of ethical maturity. However, no significant differences were found in the older group and with respondents who had management experience. So, management experience and education seem to be factors in the ethical maturity of respondents. Therefore, the study for this article focused on the following hypothesis:

Hypothesis 5 - Respondents who report having management experience will have Personal Business Ethics Scores that are equivalent to those who report having no management experience.

Kennedy (2003) found that there is a positive difference in moral judgment by educational level of the leaders' surveyed (Kennedy, pp. 71-72). He also demonstrated that there was a positive significant relationship between the amount of ethics training received by the leaders and their moral maturity levels (Kennedy, pp. 72-73). Kennedy related that "...people who develop in moral judgment are those who love to learn, seek new challenges, enjoy intellectually stimulating environments, are reflective, make plans, set goals, take risks, see themselves in the larger social contexts of history, institutions and broad cultural trends, and take responsibility for themselves and their environment" (Kennedy, p. 71). Mobley's (2002) results indicated that there was indeed a relationship between education and moral maturity; and in fact, based on her review of the literature and her own research results, Mobley (2002) concluded that regarding moral maturity "education is by far the most powerfully associated with DIT scores" (p. 71). Therefore, the study for this article focused on the following hypothesis:

Hypothesis 6 - Respondents who report having had ethics education will have Personal Business Ethics Scores that are equivalent to those who report having no such education or training.

\section{Research Statement and Methodology}

This study uses Clark's (1966) instrument to compare the results of Personal Business Ethics Scores (PBES) of Thai managers and employees. Principal comparisons are based on age, gender, and education. The research question to be answered is whether government work experience, age, education, and gender affect the moral development of individuals. The independent variables affecting one's moral development are government work experience, age, gender, and education. Survey research techniques have been successfully used to study the values and beliefs of people in the organizational culture and work environment. The analytical survey method of research has many advantages when compared to other available methods. When using self-administered questionnaires, the errors associated with interviewer subjectivity are totally eliminated. The self-administered questionnaires also offer greater anonymity, which can be extremely important when conducting research in the area of ethics (Mujtaba and Sims, 2006). Respondents are asked questions that are very personal in nature because they deal with their values, beliefs, and daily practices. Also, the self-administered questionnaires allow the researcher to objectively analyze the data and to discover statistically significant relationships. This study targeted government employees and managers in Thailand. The surveys were sent to employees and managers in the Bangkok region through training and development workshops, which were facilitated by the one of the authors. A paragraph explaining the purpose of this research and guaranteeing total confidentiality was included with each survey.

The English version of the survey was translated into Thai by one Thai expert who fluently spoke English. Then it was back-translated by another Thai-English language expert to make sure the meaning had not changed. Furthermore, five Thai students were used for the pilot study to see if they had any challenges in completing the local version of the survey. The pilot study participants did not report any difficulties using the Thai version of the survey. During the first three months of 2010, the survey instrument was provided and made available to participants in both in the English and Thai versions so as to accommodate their language preferences. A total of 400 questionnaires were provided to employees and managers who were asked to voluntarily complete the questionnaire during their workshop and return it to the distributor personally or by company mail. A total of 320 questionnaires, comprising a response rate of eighty percent, were returned. From the returned surveys, a total of 16 questionnaires were incomplete and could not be used. Therefore, a total of 304 questionnaires remained to conduct this research. Furthermore, from a convenience survey of law students in the Surin Province of Thailand, another 216 usable questionnaires were analyzed for comparison purposes. Law students completed the survey prior to a class discussion regarding ethics and laws governing business behavior.

The questionnaire used consists of eleven questions which represent the Personal Business Ethics Scores (PBES). The PBES represents a score between 11, indicating low personal business ethics, to 55, indicating very high personal business ethics. A t-test at the $\mathrm{p}<0.10$ level of significance is used to determine if there are differences in 
the responses of different groups. The 0.10 level of significance has been chosen because it is an appropriate level of significance for social science research. This study used the SPSS software program as a database to evaluate the hypothesis at the specified level of significance. The following paragraphs and explanations are geared toward each hypothesis and its explanation.

hypothesis I states that individuals who are 25 years of age or younger $\left(\mathrm{X}_{1}\right)$ will have Personal Business Ethics Scores (PBES) that are equivalent to or greater than those individuals who are 26 years of age or older $\left(\mathrm{X}_{2}\right)$. The alternative hypothesis states that individuals who are 25 years of age or younger will have PBES that are lower than those individuals who are 26 years of age or older.

Ho: $\quad \mathrm{X}_{1} \geq \mathrm{X}_{2}$

$\mathrm{H}_{1}: \quad \mathrm{X}_{1}<\mathrm{X}_{2}$

A t-test at a $10 \%$ level of significance was used to test the hypothesis. Table 1 shows the results of the t-test. The PBES mean of individuals 25 years of age or younger is 42.405 , and the PBES mean for individuals 26 years of age or older is 42.518 , with a t-test statistic of -0.1151 and a p-value significance of 0.908 .

**** See Table $1 * * * *$

The results for the first hypothesis indicate that the PBES mean value for individuals 26 years of age or older are the same as the PBES value for individuals 25 years of age or younger. The first hypothesis regarding age is supported since the PBES means of younger and older respondents are the same. So, respondents 25 years of age and younger had similar PBES scores as those who were 26 years of age or older. This result is inconsistent with previous research and does not support the moral development theory that age is a factor in moral development. It shows that government employees in Thailand who are 26 years of age or older are at the same level of moral development as those individuals who are 25 years of age or younger. These findings suggest that factors other than age are influencing the high moral maturity or "sophistication" of these respondents form the government in Thailand.

The second hypothesis states that "Government employees will have Personal Business Ethics Scores that are similar to the PBES means of law students." Since the $\mathrm{t}=15.44$ and it falls outside of the critical values as well as the fact that the p-value is less than 0.05 , this hypothesis cannot be supported. Government employees have a significantly higher PBES mean than law students in Thailand. Perhaps working for the government is a significant factor in doing what is "right," standing up for honesty and integrity, and making sure decisions are fair to all parties.

\section{**** See Table $2 * * * *$}

Hypothesis three states that "Individuals who have five or more years of formal college education (masters degree and above) will have Personal Business Ethics Scores that are equivalent to the PBES means of individuals who four years of college education or less (bachelors degree or less)." Table 3 shows the results of the analysis; and consequently this hypothesis cannot be rejected since there are no significant differences between the PBES means of the two groups. It should be pointed that the sample of those with master's degree is very small, and consequently future studies should include a larger number of people with advanced degrees.

**** See Table $3 * * * *$

Hypothesis four states that "Males will have Personal Business Ethics Scores that are equivalent to the PBES means of females." Table 4 shows the results of the analysis at the $90 \%$ confidence level and this hypothesis is rejected since there are significant differences between the PBES means of the two groups. Female respondents had higher scores. Therefore, male and female PBES means of these government employees appear to be statistically dissimilar $(\mathrm{t}=-1.9$ and $\mathrm{p}$-value $=0.06)$.

$* * * *$ See Table $4 * * * *$

Hypothesis five states that "Respondents who report having management experience will have Personal Business Ethics Scores that are equivalent to the PBES means of those who report having no management experience." Table 5 shows the results of the analysis; and consequently this hypothesis cannot be rejected since there are no significant differences between the PBES means of the two groups. The PBES means of these government employees with management experience appear to be statistically similar to those who reported no management experience $(\mathrm{t}=1.038$ and $\mathrm{p}$-value $=0.30009$ ).

**** See Table $5 * * * *$

The last hypothesis states that "Respondents who report having had ethics education will have Personal Business Ethics Scores that are equivalent to those who report having no such education or training." Table 6 shows the 
results of the analysis; and thus this hypothesis is rejected at the $90 \%$ confidence level. The PBES means of these government employees who have had an ethics course at the college or university appear to be statistically higher than those who reported having had no ethics course in college $(t=1.81$ and $p$-value $=0.0717)$. So those who reported having an ethics course at the college level did have higher scores on ethical maturity.

**** See Table $6 * * * *$

Overall, the results indicate that those with experience in working for the public sector have significantly higher PBES means than those student respondents who are studying to become lawyers. Gender is a factor since women had higher scores. The variables of age and education did not produce any statistically significant results among the government employees in Thailand. However, significantly, having taken an ethics course at the college level did demonstrate a statistical significance since those with such education had higher scores.

\section{Implications, Limitations and Recommendations}

Some researchers claim that such factors as gender, age, and education make a difference in the ethical maturity of individuals in Thailand as well as people in other countries. Usssahawanitchakit (2008) in a study of the relationship between business ethics and environmental characteristics and earnings quality of small- and medium-sized enterprises (SMEs) conducted in the south of Thailand, indicated that both business ethics and environmental characteristics have significant positive associations with the earnings quality of the firms. Usssahawanitchakit explained the results, to wit: "Then, business ethics likely appears to encourage firms in presenting and reporting financial information through the earnings quality of financial statements. Accordingly, business ethics tends to have a positive association with earnings quality. Similarly, SMEs with greater ethical consideration in businesses are likely to focus more on stakeholder orientation and attempt to report higher earnings quality" (2008, p. 4). Accordingly, Usssahawanitchakit advised that "managers should effectively understand, manage, and utilize business ethics and environmental characteristics to improve earnings quality, sustain, and succeed in the present and future operations" (2008, p. 9). Singhapakdi, et al (2000), in their study of Thai marketing managers who were attending MBA programs in Thailand, also sought to ascertain the influence of corporate ethical values. They found that "Thai managers in organizations with higher levels of ethical values tend to have more ethical intentions than managers with lower levels of ethical values...Apparently...in the Thai culture (perhaps other similar cultures in the region), the ethical climate of an organization is also an important factor of ethical decisions of managers" (Singhapakdi, et al, 2000, p. 280). They further explained that "given that ethical intentions positively influence ethical behavior..., an important implication from this finding is that if top management wants its employees to behave ethically, it should create an ethical climate in the organization. This also includes establishing a code of ethics and strongly enforcing it" (Singhapakdi, et al, 2000, p. 280). However, Marta and Singhapakdi (2005), in their comparative study of Thai and U.S. marketing managers, found that the Thai respondents estimated the overall harm caused by unethical marketing practices as less than the U.S. managers; and the Thai marketing managers tended to predict that unethical marketing practices will cause less harm than U.S. marketing managers did. Their results only partially supported the proposition that Thai marketing managers will be more likely than the U.S. marketing managers to condemn an unethical marketing practice done to a personal friend (Marta and Singhapakdi, 2005). Yet they found no significant differences among the Thai and U.S. respondents for the proposition that the Thai managers will perceive that their corporations have less ethical values, and "therefore, we cannot conclude Thai managers will perceive ethics to be less important for business success than American managers do" (Marta and Singhapakdi, 2005, p. 571). In their comparative study of the moral intensity of Thai and U.S. students regarding software piracy, Kini, et al (2004) found that students from the U.S. had a significantly higher moral intensity regarding software piracy than the Thai students, that the male students (both Thai and U.S.) had significantly higher moral intensity than the female students, but concerning age there was no significant difference between the moral intensity of the age groups studied. "Moral intensity" has been explained by Marta and Singhapakdi (2005) as follows: "A situation with very high moral intensity creates pressure to make a more ethical decision; where there is little moral intensity, the decision-maker may perceive little risk in behaving immorally" (p. 564).

The Thai research for this article concluded that working for the government is a significant factor in the moral maturity of respondents. While management experience, age, gender, and education variables were not statistically significant factors for these government employees in Thailand, those who were older, female, had management experience, held a masters or doctorate degree did have higher business ethics scores than their counterparts. So, it can be suggested that education, age, gender, and management experience can increase a person's level of ethical maturity in the workplace. Regarding the variable of ethics education, the Thai study demonstrated a positive relation to business ethics on the PBES survey. Thus, a key question emerges: What is the nature of ethics education and training in Thailand, since apparently based on the results herein, it is morally efficacious? 
Of course, before introducing an education or ethics training program, managers need to develop a much fuller picture of why their employees are tempted to make unethical decisions. Studies by previous researchers demonstrate that education is one of the strongest correlates to and predictors of cognitive moral development and ethical maturity (Haung,, 2006, p. 56; Hyppolite, 2003, p. 137; Mobley, 2002, p. 74). This study concludes that ethics specifically can be taught, should be taught, and that educational programs must integrate the study of ethical and moral development in their curriculum since ethics instruction has the potential to make managers and employees less likely to engage in unethical behavior. Ethics education must also inculcate principled ethical reasoning skills into today's very competitive business environments so that ethics education can lead to enhanced moral development, better moral reasoning, and thus more moral behavior in the workplace.

\section{Conclusion}

This research was designed to determine whether government work experience, education, age, gender, and management experience, gained through the maturation continuum or process, are related to ethical decision-making. This research has concluded that working for the government is a significant factor in the moral maturity of respondents. Gender is also a factor in moral maturity. Business ethics, moreover, is positively influenced by ethics education. While management experience, age, and education variables were not statistically significant factors for these government employees in Thailand, those who were older, had management experience, and held a masters or doctorate degree did have higher business ethics scores than their counterparts. So, it can be suggested that education, age, gender, and management experience can increase a person's level of ethical maturity in the workplace. Future researchers, therefore, should collect more data from respondents in Thailand as well as other countries to see how their scores compare with these findings. What it means to be moral and what factors influence ethical reasoning, moral development, and moral conduct are very important issues academically as well as in the private and public sector workplaces.

\section{References}

Ames, Roger T. (2009). Confucian Moral Imagination and the Global Condition: Knowledge and Ethics Must Go Together. Humanities Public Forum II Lecture at the Institute of International Studies of Ramkhamhaeng University. August 18, 2009, 9:30 am - 12:00 pm, at the IIS Building, Bangkok, Thailand.

Cavico, F. J. and Mujtaba, B.G. (2009). Business Ethics: The Moral Foundation of Leadership, Management, and Entrepreneurship (2 $2^{\text {nd }}$ edition). Pearson Custom Publications. Boston, United States.

Clark, J. W. \& Clark, S.J. (1966). Religion and moral standards of American businessmen. Cincinnati: Southwestern Publishing Co.

Danon-Leva, Elizabeth (2006). A Cross-Cultural Comparison of Business Ethics among Graduate Business Students in the United States and Hong Kong. Doctoral Dissertation. Nova Southeastern University. Ft. Lauderdale, Florida, United States.

Gilligan, C. (1982). In a difference voice: Psychological theory and women's development. Cambridge, MA: Harvard University Press.

Gilligan, C. (1977). In a different voice: Women's conception of self and morality. Harvard Educational Review, 47, 481-517.

Heron, W. T. (2006). An examination of moral development and ethical decision making of information technology professionals. Doctoral Dissertation. Nova Southeastern University. Ft. Lauderdale, Florida, United States.

Huang, Chunlong (2006). Cross-Cultural Ethics: A Study of Cognitive Moral Development and Moral Maturity of U.S. and Japanese Expatriate Managers in Taiwan and Taiwanese Managers. Doctoral Dissertation. Nova Southeastern University. Ft. Lauderdale, Florida, United States.

Hyppolite, Aranck Aurel (2003). The Influence of Organizational Culture, Ethical Views and Practices in Local Government: A Cognitive Moral Development Study. Doctoral Dissertation. Nova Southeastern University. Ft. Lauderdale, Florida, United States.

Kennedy, William Joseph (2003). A Study of the Moral Reasoning Skills of Proactive and Reactive Organizational Management. Doctoral Dissertation. Nova Southeastern University. Ft. Lauderdale, Florida, United States.

Khruasuwan, Montiche (2000). The Impact of Thai Culture on Participative Management Theory and Practice. Doctoral Dissertation. Nova Southeastern University. 
Kini, Ranjan B., Ranakrishna, Hindpur V., and Vijayaraman, Bindiganavale S. (2004). Shaping of Moral Intensity Regarding Software Piracy: A Comparison Between Thailand and U.S. Students. Journal of Business Ethics, 49, pp. 91-104.

Kohlberg, L. (1984). The Philosophy of Moral Development. San Francisco: Harper and Row.

Kohlberg, L. (1969). Stage and sequence: The cognitive moral development approach to socialization. In D. Grosling (ed.), Handbook of socialization theory and research. Chicago: Rand McNally.

Lau, D.C. (Translated) (1979). Confucius: The Analects. England, The United Kingdom: Penguin Books.

Marta, Janet K.M. and Singhapakdi, Anusorn (2005). Comparing Thai and US businesspeople. International Marketing Review, 22(5), pp. 562-77.

Mobley, Sandra E. Ford (2002). The Study of Lawrence Kohlberg's Stages of Moral Development Theory and Ethics: Considerations in Public Administration Practices. Doctoral Dissertation. Nova Southeastern University. Ft. Lauderdale, Florida, United States

Mujtaba, B. G. (2010). Business ethics of retail employees: How ethical are modern workers? ILEAD Academy Publications; Davie, Florida, United States.

Mujtaba, B. G. (2008). Task and relationship orientation of Thai and American business students' based on cultural contexts. Research in Higher Education Journal, 1(1), 38-57.

Mujtaba, B. G. (1997). Business Ethics Survey of Supermarket Managers and Employees. UMI Dissertation Service. A Bell \& Howell Company. UMI Number: 9717687.

Mujtaba, B. G., Chawavisit, C., and Pattaratalwanich, P. (2010). Conflict Management Styles of Law Students in Thailand: a Study of Age and Gender. Journal of Global Business and Management, 1(2), 14-32.

Mujtaba, B. G., Pattaratalwanich, P. and Chawavisit, C. (2009). Business Ethics Perspectives of Thai Law Students: a Study of Age and Gender in Moral Development. Journal of Leadership, Accountability and Ethics, 7(3), 94-108.

Mujtaba, B. G., Cavico, F. J., McCartney, T. O., and DiPaolo, P. T. (2009). Ethics and Retail Management Professionals: An Examination of Age, Education, and Experience Variables. American Journal of Business Education,2(3), 13-25.

Mujtaba, B. and Sims, R. L. (2006). Socializing Retail Employees in Ethical Values: The Effectiveness of the Formal versus Informal Methods. Journal of Business and Psychology, 21(2), 261-272.

Rassameesukhanon, Thanakul. (2008). Employees' Perception of Ideal and Actual Leaders Compared to Managers' Perception of Ideal and Actual Leaders: A Comparative Study in Thailand. Ramkhamhaeng University International Journal, Vol. 2, No. 1, pp.83-87.

Resanond, Soipetch. (2002). Organizational Commitment and Work-Related Cultural Values: A Cross-Cultural Study of Japanese and Thai Managers in Multinational Corporations in Thailand. Doctoral Dissertation. Nova Southeastern University.

Singhapakdi, Anusorm, Salyachivain, Somboom, Virakul, Buscaya, and Veeerayangkur, Vinch (2000). Some Important Factors Underlying Ethical Decision Making of Managers in Thailand. Journal of Business Ethics, 27, pp. 271-284.

Sungkhawan, J. (2000). A Study of Relationships Between Cultural Values and Economic Variables in Thirteen Countries in Asia and Asia Pacific. Doctoral Dissertation. Nova Southeastern University. Fort Lauderdale, Florida, United States.

Suwannachin, Kittphat. (2003). The Relationship among Leadership Styles, Work-Related Cultural Values, and Organizational Outcomes in Higher Education Institutions in Thailand. Doctoral Dissertation. Nova Southeastern University.

UNESCO. (July 2002). UNESCO Institute for Statistics - Thai Literacy Policy. Retrieved on August 22, 2009 from: http://www.accu.or.jp/litdbase/policy/tha/index.htm.

Ussahawanitchakit, Phapruke. (February 1, 2008). Effects of business ethics and environmental characteristics on earnings quality of SSEs in the south of Thailand. Journal of Academy of Business and Economics. Retrieved September 25, 2009 from: http://www.thefreelibrary.com.

Venezia, Chiulien Chuang. (2004). The Ethical Reasoning Abilities of Accounting Students: Comparison between the U.S. and Taiwan. Doctoral Dissertation. Nova Southeastern University. Ft. Lauderdale, Florida, United States. 
Table 1. Thai PBES: Age

\begin{tabular}{|c|c|}
\hline Younger & \\
\hline Sample Size & 74 \\
\hline Sample Mean & 42.405 \\
\hline Sample Standard Deviation & 6.39 \\
\hline \multicolumn{2}{|l|}{ Older } \\
\hline Sample Size & 139 \\
\hline Sample Mean & 42.5180 \\
\hline Sample Standard Deviation & 7.0390 \\
\hline \multicolumn{2}{|l|}{ Two-Tailed Test } \\
\hline$t$-Test Statistic & -0.1151 \\
\hline$p$-Value & 0.908463 \\
\hline
\end{tabular}

Table 2. Thai PBES: Government Employees Vs. Law Students

\begin{tabular}{lr}
\hline \multicolumn{2}{c}{ Government Employees } \\
Sample Size & 304 \\
Sample Mean & 42.872 \\
Sample Standard Deviation & 6.78 \\
$\quad$ Law Students & \\
Sample Size & 216 \\
Sample Mean & 34.0900 \\
Sample Standard Deviation & 5.7970 \\
\multicolumn{2}{l}{ Two-Tailed Test } \\
p-Value
\end{tabular}

Table 3. Thai PBES: Education

\begin{tabular}{|c|c|}
\hline Bachelo & \\
\hline Sample Size & 260 \\
\hline Sample Mean & 42.85 \\
\hline Sample Standard Deviation & 6.73 \\
\hline \multicolumn{2}{|c|}{ Masters and Above } \\
\hline Sample Size & 44 \\
\hline Sample Mean & 43.0000 \\
\hline Sample Standard Deviation & 7.1400 \\
\hline \multicolumn{2}{|c|}{ Two-Tailed Test } \\
\hline$t$-Test Statistic & -0.1355 \\
\hline$p$-Value & 0.892291 \\
\hline
\end{tabular}

Table 4. Thai PBES: Gender

\begin{tabular}{|c|c|}
\hline Males & \\
\hline Sample Size & 155 \\
\hline Sample Mean & 42.148 \\
\hline Sample Standard Deviation & 7.27 \\
\hline \multicolumn{2}{|c|}{ Females } \\
\hline Sample Size & 149 \\
\hline Sample Mean & 43.6200 \\
\hline Sample Standard Deviation & 6.1650 \\
\hline \multicolumn{2}{|c|}{ Two-Tailed Test } \\
\hline$t$-Test Statistic & -1.9004 \\
\hline$p$-Value & $0.058327 *$ \\
\hline
\end{tabular}

*Significant at the $90 \%(0.10)$ level of significance. 
Table 5. Thai PBES: Management Experience

\begin{tabular}{lr}
\hline \multicolumn{2}{c}{ Had Mgmt Experience } \\
Sample Size & 173 \\
Sample Mean & 43.225 \\
Sample Standard Deviation & 6.651 \\
$\quad$ No Management Experience & 131 \\
Sample Size & 42.4100 \\
Sample Mean & 6.9450 \\
Sample Standard Deviation $\quad$ Two-Tailed Test & \\
t-Test Statistic & 1.0380 \\
$p$-Value & 0.300091 \\
\hline
\end{tabular}

Table 6. Thai PBES: Ethics Course in College

\begin{tabular}{|c|c|}
\hline \multirow{2}{*}{\multicolumn{2}{|c|}{ Had an Ethics Course }} \\
\hline & \\
\hline Sample Size & 235 \\
\hline Sample Mean & 43.2512 \\
\hline Sample Standard Deviation & 6.498 \\
\hline \multicolumn{2}{|c|}{ Did not have an Ethics Course } \\
\hline Sample Size & 69 \\
\hline Sample Mean & 41.58 \\
\hline Sample Standard Deviation & 7.57 \\
\hline \multicolumn{2}{|c|}{ Two-Tailed Test } \\
\hline$t$-Test Statistic & 1.8071 \\
\hline$p$-Value & $0.071747 *$ \\
\hline
\end{tabular}

*Significant at the $90 \%(0.10)$ level of significance. 